\title{
Research Approach in Enterprise Engineering: A Matter of Engineering
}

\author{
Niek J. Pluijmert ${ }^{1,2}$, Wolfgang A. Molnar ${ }^{3}$, and Henderik A. Proper ${ }^{3}$ \\ 1 Radboud University, Nijmegen \\ 2 INQA Quality Consultants B.V., P.O. Box 195, 4130 ED Vianen, The Netherlands \\ ${ }^{3}$ CRP Henri Tudor, 29, avenue John F. Kennedy, L-1855 Luxembourg-Kirchberg \\ pluijmert@inqa.nl, email@wolfgang-molnar.com, erik.proper@tudor.lu
}

\begin{abstract}
Enterprises encounter serious problems in keeping pace with ever faster changing markets. Enterprise Engineering (EE) is an emerging field that is promising in providing solutions. Doing research in this field, requires choosing an appropriate research method for different parts of the research. This is the composition of the research method from known research methods, we call this engineering of the research approach. We structure available methods, approaches and techniques for qualitative research in information systems. We describe three epistemologies and discuss the different qualitative research methods and differences and similarities between them. For our research on EE that applies transaction cost economics in designing enterprises using the notions of Enterprise Ontology and Enterprise Architecture we combine a positivist approach during literature study with an interpretivist approach during Action Research.
\end{abstract}

Keywords: Enterprise Engineering, Research Approach, Qualitative Research Methods, DEMO, Design Science, Action Research.

\section{Introduction}

Organizations change rapidly because they must keep pace with ever faster changing markets. But organizations encounter serious problems in controlling changes. In trying to adapt to necessary changes, organizations may perform projects. In international surveys 1 it is found that many strategic projects fail. More in detail it is found that most of the large (labor costs over $\$ 10$ million) projects fail or are challenged, while small (labor costs less than $\$ 1$ million) succeed. The top 3 causes are (lack of) involvement of qualified users, support by management (fast decision making) and clear objectives. Tools and infrastructure are in the 10th place. So, technical factors (tools and infrastructure) are less important than social factors (the top 3 causes) for projects to be successful. Dietz \& Hoogervorst [1] investigated to what extend enterprises derive success from their strategy: the majority of the strategic initiatives fail. They distinguish two factors, one is the strategy chosen and its adaptation over time and the other is the implementation

\footnotetext{
1 International Standish Group 2010. 
of the chosen strategy. They argue that research has shown that strategic failure is mostly the avoidable result of inadequate strategy implementation. The impact of IT on enterprises is increasingly acknowledged to be fundamentally strategic as new IT penetrates progressively the core business processes [2]. So the integration of IT in the enterprise is necessary because then the emphasis is put on the social factors and less on technical factors.

An answer to these problems can probably be found with Enterprise Engineering (EE). EE is an emerging field and combines relevant parts of traditional organization sciences and information system sciences.

Chen \& Vernadat [3] define EE as the art of analyzing, restructuring, designing - or redesigning - and, as much as possible, optimizing whole or part of a business entity with respect to its mission and objectives, where a business entity is any socio-economic system built to produce products or services. Vernadat [4] states that the current challenge is to build agile enterprises, which he describes as systems of cooperating business entities that can belong to different legal entities and that can be easily tailored to fast changing conditions. Business entities are combinations of business processes. Chen, Doumeingts \& Vernadat 5] define Enterprise Architecture (EA) as the description of the basic arrangement and connectivity of parts of a system. They state that the concept of architecture is closely related to engineering.

According to Dietz [6] the basic premise of EE is that an enterprise is a designed system and for the design of an enterprise the notions of Enterprise Ontology (EO) and Enterprise Architecture (EA) are crucial. EO provides a means to make a model of the construction of an enterprises at a high level of abstraction, i.e. completely independent of its implementation. EO also has a precise definition of a business process, that consists of transactions. EA is defined as the set of design principles that an enterprise applies in designing itself. As is known from engineering practice, without these principles the design freedom would be practically unlimited which is of course not desirable.

Although the definitions of EE in [3.5] compared with the definition in [6] are different, their definitions of business process are very much alike. That is why we feel $\mathrm{EE}$ is a good candidate to offer solutions for the above mentioned problems enterprises encounter to keep pace with the ever faster changing markets.

Fields like EE require specific research methodologies with which one can devise artifacts and at the same time study how useful they are. The reason for this article is that we want to make clear (for the readers as well as for ourselves) the position that we take towards research in EE and what are accepted ways of doing research in this field. We base ourselves on the work of Myers [7] about qualitative research in IS which is available in an updated version as a website 2 .

EE is about organizations and information systems (IS). We approach the research from the IS side and we realize we also could have taken an approach from the organization sciences. We take the approach from the IS side because it is about engineering and also because this fits best with our background, that is in IS.

${ }^{2}$ http://www. qual. auckland.ac.nz/ 


\section{Research Objectives and Research Questions}

The objective of our research is to better understand the role of transaction costs in designing enterprises. This is the operationalisation of our aim in Section 1 to make clear what accepted ways of doing research in the EE field are. The notions of EE, EO and EA as described in the previous Section 1 3456] provide the theoretical basis for designing enterprises as combinations of business processes. Costs are an important aspect in organizing an enterprise. Williamson [8] characterizes transaction by 3 dimensions and 3 governance structures. The dimensions are uncertainty, the frequency with which transactions recur and the degree to which investments are transaction specific. The governance structures are market, internal or an intermediate mode of organization. The characteristics of the dimensions determine where transactions can best be located: on the market, internal or in an intermediate mode. This theory can provide evidence to support the way transactions as defined in [6] should be combined into business entities that form the agile enterprises as defined in [3] that we need to face nowadays problems of ever faster changing markets. This leads to the central research question how can agile enterprises be designed in practice by applying Transaction Cost Economics to Enterprise Engineering?

\section{Literature Review}

First we will give the definition of Enterprise Engineering we will use and that comprises the definitions from [3456]. In accordance with the AppEER- website $\sqrt{3}$ we define EE as the overarching term for the disciplines (among which are both EA and EO, see Section 1, as well as business process management, enterprise modeling, enterprise transformation) that study the engineering of socio-technical systems. With socio-technical systems we mean specifically information systems (IS) in their full alignment with their human / organizational context. Because EE is an emerging field of research without (yet) commonly accepted research approaches, we investigate in this chapter research approaches for IS research to find an approach for EE. There are different ways to structure methods, approaches and techniques that researchers use. We want to study organizational and managerial aspects of IS and we want to study in depth a limited number of cases. Because of these reasons quantitative (e.g. statistical) methods are not appropriate, so we will describe qualitative methods. In doing so, we follow Myers [7. In Figure 1 we schematically give the relation between qualitative research methods and epistemology that we will explain. We start to discuss research approaches from the viewpoint of epistemology. Next, we take into account different methodologies and last we discuss differences between and possible combinations of the different methodologies.

\footnotetext{
3 Appeer.ee-team.eu
} 




Fig. 1. Epistemology and Qualitative Research Methods

\subsection{Epistemology}

Epistemology is a branch of philosophy that studies the nature and scope of knowledge, more specifically it is concerned with what is acceptable knowledge in a certain field. Orlikowski \& Baroudi 9 made an inventory of 155 information systems research articles published from 1983 to 1988. They examined the articles for the underlying epistemology and could classify the articles as positivist, interpretive or critical. This classification is also proposed by Chua [10].

Positivism. Positivist studies are primarily meant to test theory. Researcher and object of study are independent. Researchers assume an objective physical and social world that exists independent of human beings. This is the traditional approach of natural and social research 9 . Applied to IS research, it is applicable for situations where the designer wants to evaluate if the designed artifact works according to the specifications of the design. Because a positive approach does not take into account the effect on human beings, this approach is less suited for studying the effect of IS on the human beings that work with the IS.

Interpretivism. In interpretivism one asserts that reality is a social product and hence incapable of being understood independent of the social actors that construct that social reality. In interpretive research the researcher tries to understand how members of a social group by their participation in the social processes, help to constitute their social action. So, no objective reality exists and the perception and the importance of subjective meanings is emphasized. Applied to IS research, part of the evaluation is also the way the designed artifact works in its environment of human actors or, in other words, the judgment if the designed artifact works according to the user's requirements. The evaluation results can lead to improvements of the designed artifact.

Criticism. The critical researcher tries to critically evaluate and transform social reality, this is opposed to the other two research perspectives that confine themselves to predict or explain social reality. The idea within criticism is that social 
reality is historically constituted and that by critiquing existing social systems the contradictions and conflicts can be revealed so that people can act to change the existing system. Again, applied to IS research, the designed artifact is not only observed in its working environment, but the researcher also tries to influence the environment. At this point, we must discern between the following two things: first we have the content of the artifact and second we have the project that implements the artifact. The researcher can have two roles: the role of defining the content of the artifact and/or the role of project leader. The researcher can have the role of project leader in an interpretive or critical setting. Only if the researcher also determines the content of the artifact, we speak of a critical role for the researcher. Thinking of nowadays social reality, where IS is supposed to have a supportive role in organizations, one should be careful in applying the critical approach. This seems to be confirmed by Orlikowski \& Baroudi [9] who classified none of the studied articles as critical.

\subsection{Qualitative Research Methods}

In the last part of Section 1 we wrote that we follow Myers [7] in his description of qualitative research in information systems. He argues that for studying social phenomena, a qualitative approach is most appropriate and in Section 2 we explained why this applies to our research. A research method is the strategy of inquiry that is used to design the research and collect data. This implies that the research method can be used with every of the three epistemologies. Here, we will discuss action research (AR) and case study research (CSR) as qualitative research methods. As we shall see, AR has much in common with design science (DS) research, we will also discuss DS research and the distinction between AR and DS research.

Action Rsearch. AR originally aims to contribute to the solution of immediate problematic situations of people and to the body of knowledge of the social science community. It had much difficulties in being acknowledged as a good research approach for IS. Baskerville \& Wood-Harper [11] address the relationship between AR and consulting: action researchers are required to defend their method against the challenge that "this is nothing but consultancy!" At that time Baskerville recognized that AR was not a main stream social science technique that was transported to the IS field. He thinks that maybe in the IS field AR will finally flourish. In Baskerville \& Myers [12] AR has proven its added value in IS research as a method to solve current practical problems while expanding scientific knowledge. The trigger for AR has been the frequent calls for IS researchers to make their research more relevant.

Case Study Research. The term case study has multiple meanings. It can be used to describe the unit of analysis or to describe a research method. As the unit of analysis, case study can be used in conjunction with e.g. AR. As a research method there are numerous definitions and Yin [13] defines the case study as a research strategy that attempts to examine (a) a contemporary phenomenon in its real-life context especially when (b) the boundaries between phenomenon 
and context are not clearly evident. Benbasat, Goldstein et al. 14 add to the definition of Yin that multiple methods of data collection are employed to gather information. They sum up a list of 11 key characteristics for case studies, see Table 1 .

Table 1. Key characteristics of case studies 14

1. Phenomenon is examined in a natural setting

2. Data are collected by multiple means

3. One or few entities (person, group or organization) are examined

4. The complexity of the unit is studied intensively

5. Case studies are more suitable for the exploration, classification and hypothesis development stages of the knowledge building process; the investigator should have a receptive attitude towards exploration

6. No experimental controls or manipulation are involved

7. The investigator may not specify the set of independent and dependent variables in advance

8. The results derived depend heavily on the integrative powers of the investigator

9. Changes in site selection and data collection methods should take place as the investigator develops new hypotheses

10. Case research is useful in the study of 'why' and 'how' questions because these deal with operational links to be traced over time rather than with frequency or incidence

11. The focus is on contemporary events

Design Science. According to March \& Smith [15] IT research studies artificial as opposed to natural phenomena, DS is concerned with devising artifacts to attain goals. They define a framework that consists of four types of products (constructs, models, methods and implementations) and four research activities (build, evaluate, theorize and justify). Build and evaluate are design science activities and theorize and justify are natural science activities. In a later article of Hevner [16] IS research is characterized by two paradigms: behavioral and design science. From the business-to-IT alignment model from Henderson \& Venkatraman [17. the framework from Hevner is extended with a relevance part which provides requirements from the environment (business needs) for the IS research. In [16] IS research is defined as a three cycle method: relevance cycle and rigor cycle with the design cycle in the middle, see Figure 2, The goal of behavioralscience research is truth (relevance cycle). The goal of design-science research is utility (design cycle). In the rigor cycle the foundations and methodologies that together form the knowledge base for accomplishing IS, research are provided and new additions to the knowledge base are made.

Hevner [16] is a reaction to the essay of Iivari [18] in which is argued that the distinction between IS as DS and IS as inventions from practitioners, is the specification of a reasonably rigorous constructive research method for building IT artifacts. 


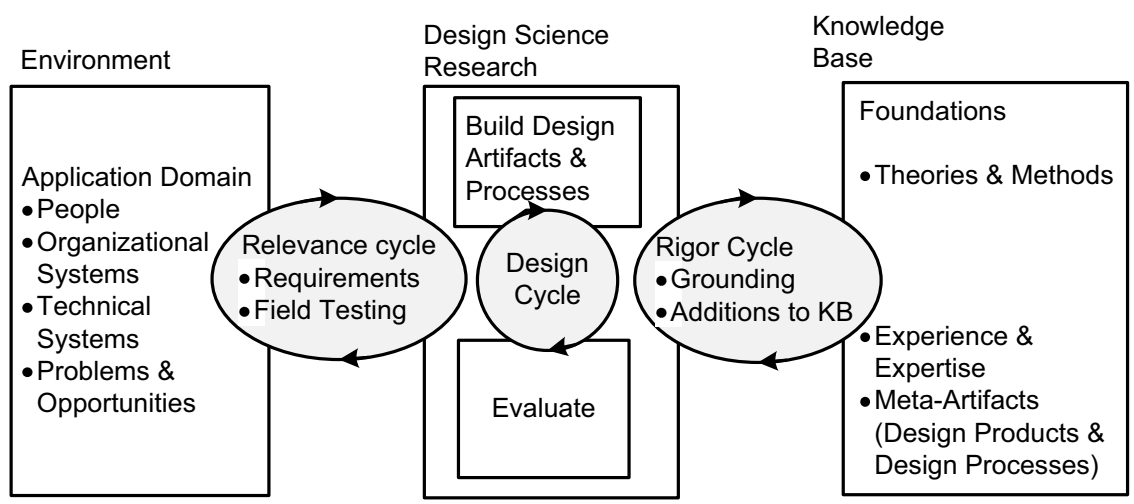

Fig. 2. Three Cycle view of Design Science, Hevner [16]

Peffers, Tuunanen et al. [19] developed a design science research methodology (DSRM), because they felt that the lack of such a methodology in IS research could have contributed to the slow adoption in IS. Peffers et al wanted to design a commonly accepted framework. Therefore they studied influential research and used a consensus-building approach to design the framework. This framework consists of six activities and has four possible entry points for research, see Figure 3 .



Fig. 3. Design Science Research Methodology, Peffers et al. 19]

\subsection{Differences and Similarities between DS and AR}

In literature discussion can be found whether AR and DS are similar or not. Iivari [18] differentiates between DS and AR: DS has its roots in engineering and AR has its roots in the socio-technical design movement. Iivari \& Venable [20] argue that DS research and AR are decisively dissimilar: they discern on the one hand purely technical problems and innovations and on the other sociotechnical problems and innovations. Iivari \& Venable [20] argue that DS research focuses on constructing new and innovative ways to solve class(es) of problems, 
thus creating new reality. In many situations AR is conducted to understand phenomena like the working of complex organizational situations and human behavior and come to improvements to that. So, DS concentrates on constructing new artifacts, while AR concentrates on improving the use of artifacts in their meant environment. Järvinen [21] argues that AR is similar to DS. He does so by trying to collect the characteristics which describe the nature of AR in general on the one hand and the characteristics of DS on the other hand. He characterizes AR with 7 characteristics and DS with 6 characteristics. He concludes that it seems there is a very high fit between the two sets of characteristics. In table 2 the corresponding characteristics are placed opposite to each other. So we see that Järvinen and Iivari do not disagree so much, but that the involvement of the environment in the evaluation is seen as an important dissimilarity by Iivari, while Jrvinen considers this a similarity.

\subsection{Combining AR and DS to Overcome Problems with Traditional AR}

Iivari \& Venable 20] describe also situations where AR and DS research can be combined. When we take in mind the nowadays practices of software development like Agile and Scrum and also a management method as Lean, it seems that a shift towards AR is driven by the environment's demand to respond faster 22. They define IT artifacts as ensembles, by which is reflected that structures of the organizational domain are inscribed into the artifact during its development and use 22. Orlikowski 23] identifies the prevailing DS approach as "build and then evaluate". AR aims at linking theory with practice, and thinking with doing. They propose to combine the two methods into a new method action design research $(\mathrm{ADR})$ and in this way recognize that the artifact emerges from interaction with the organizational context. The method has 4 stages (problem formulation; building, intervention and evaluation (BIE); reflection and learning; formalization of learning) and 7 principles, see Figure 4. In the BIE-stage they discern IT-dominant BIE and organization-dominant BIE. In IT-dominant BIE artifacts are initially evaluated by practitioners and only more mature artifacts are evaluated by end-users. In organization-dominant BIE where the emphasis is on innovation in organizational intervention, each iteration is evaluated by both practitioners and end-users.

\subsection{Project Management}

The methods described before put emphasis on the what and pay less attention to the how. The what and the how correspond with the two roles of the researcher, i.e. the role of defining the content of the artifact and the role of project leader (see Subsection 3.1). A method that describes the how is that of Mulder in [24]. He applied AR and defined a project management method for AR projects, see Figure 5. He clarifies the coherence between a participative project approach and decision making in an organization. He found a large added value of this project management approach. Speed, quality and involvement of parties and by 
Table 2. Similarities of the fundamental characteristics of action research and design science according to Järvinen [20]

\begin{tabular}{|c|c|}
\hline Action Research & Design Science \\
\hline $\begin{array}{l}\text { AR-1: Action Research emphasizes the } \\
\text { utility aspect of the future system from } \\
\text { the people's point of view. }\end{array}$ & $\begin{array}{l}\text { DS-4: Design science's products are as- } \\
\text { sessed against criteria of value or utility. }\end{array}$ \\
\hline $\begin{array}{l}\text { AR-2: Action research produces knowl- } \\
\text { edge to guide practice in modification. }\end{array}$ & $\begin{array}{l}\text { DS-2: Design science produces design } \\
\text { knowledge (concepts, constructs, models } \\
\text { and methods). }\end{array}$ \\
\hline $\begin{array}{l}\text { AR-3: Action research means both ac- } \\
\text { tion taking and evaluating. }\end{array}$ & $\begin{array}{l}\text { DS-3: Building and evaluation are the } \\
\text { two main activities of design science. }\end{array}$ \\
\hline $\begin{array}{l}\text { AR-4: Action research is carried out in } \\
\text { collaboration between action researcher } \\
\text { and the client system. }\end{array}$ & $\begin{array}{l}\text { DS- } 5 \text { : Design science research is initiated } \\
\text { by the researcher(s) interested in devel- } \\
\text { oping technological rules for a certain } \\
\text { type of issue. Each individual case is pri- } \\
\text { marily oriented at solving local problem } \\
\text { in close collaboration with the local peo- } \\
\text { ple. }\end{array}$ \\
\hline $\begin{array}{l}\text { AR-5: Action research modifies a given } \\
\text { reality or develops a new system. }\end{array}$ & $\begin{array}{l}\text { DS-1: Design science solves construction } \\
\text { problems (producing new innovations) } \\
\text { and improvement problems (improving } \\
\text { the performance of existing entities). }\end{array}$ \\
\hline $\begin{array}{l}\text { AR-6: The researcher intervenes in the } \\
\text { problem setting. }\end{array}$ & $\begin{array}{l}\text { DS- } 5 \text { : Design science research is initiated } \\
\text { by the researcher(s) interested in devel- } \\
\text { oping technological rules for a certain } \\
\text { type of issue. Each individual case is pri- } \\
\text { marily oriented at solving local problem } \\
\text { in close collaboration with the local peo- } \\
\text { ple. }\end{array}$ \\
\hline $\begin{array}{l}\text { AR-7: Knowledge is generated, used, } \\
\text { tested and modified in the course of the } \\
\text { action research project. }\end{array}$ & $\begin{array}{l}\text { DS-6: Knowledge is generated, used and } \\
\text { evaluated through the building action. }\end{array}$ \\
\hline
\end{tabular}

consequence the acceptance of the solution is by far better than a distant expert judgment. A participative approach considers organization design as a change process in which parties unfreeze from their current (undesired) situation, start discovering new possibilities for change and establish this in a new design. 


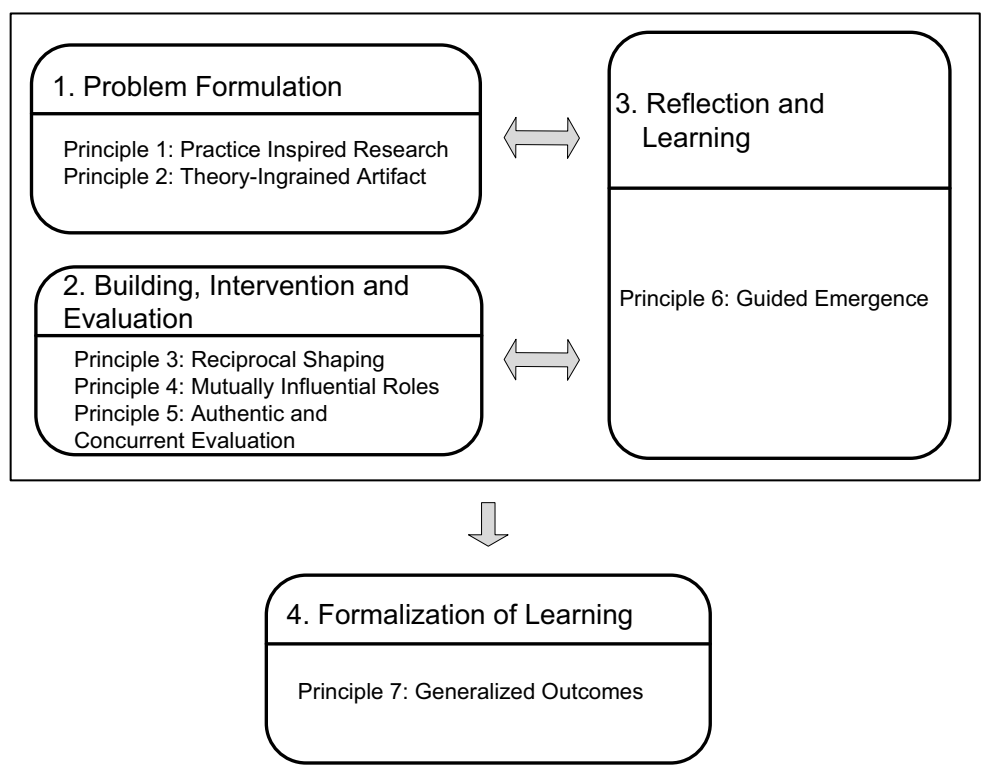

Fig. 4. Action Design Research (ADR) acc. Sein et al. 22]

\section{Our Research Approach}

In our research we will start studying theory and literature on transaction cost economics (TCE). The researcher takes in this a positivist position while performing the design cycle and the rigor cycle. This is a necessary step to take for us in order to ground our experiences from practice in theory and existing literature. This should lead to a framework for applying TCE to EE. We want to apply this framework in practice and learn from it. For this approach a qualitative research method is appropriate, not a quantitative. According to Orlikowski 9] and Figure 1 this means that we need an interpretive or critical stance. The critical stance implies that the researcher wants to change the social reality of the changing organization. This does not fit to a role as consultant as we have in our projects. In the project, we take decisions in the project management process and in the change process we propose the solutions and do interventions. According to Figure 1 this means that the researcher needs an interpretive role. As argued in Section 3 we follow 725] in using a qualitative approach in our research. We already discussed the differences and similarities between DS and AR [20,21,22 23] and we repeat here that an AR approach fits best in an Agile environment where the use of methods like Scrum and Lean is encountered. We use case studies for defining the unit of analysis. For the setup and execution of projects, we adopt Mulder [24, see Figure [5. In Table 3] we summarize our research approach. 



Fig. 5. Coherence between project approach and decision making in organization design 24

Table 3. Summary of research approach

\begin{tabular}{|l|l|}
\hline Objective & $\begin{array}{l}\text { Enterprise design by applying transaction cost economics to } \\
\text { EE }\end{array}$ \\
\hline Focal level & Role of transaction costs in enterprise design \\
\hline Epistemology & Positivist for theoretical study, Interpretivist in cases \\
\hline Research Method & Action Research \\
\hline $\begin{array}{l}\text { Project Management } \\
\text { Method }\end{array}$ & Participative \\
\hline
\end{tabular}

\subsection{Activities Already Performed}

In Section 1 we followed Dietz [6] that Enterprise Ontology (EO) is a crucial notion for EE. A method for EO is DEMO and that method has been applied in a number of projects. As part of this research, we investigated finished DEMO projects for what the added value of DEMO as an EE method in projects has been. A first round of interviews with the stakeholders of these DEMO projects and the founders of DEMO has been conducted in April - June 2012. The notion "DEMO project" means that the people involved in those projects acknowledge them as DEMO project. All projects investigated are claimed to be successful. After the first, more general, round of interviews, there will be a second round of interviews, that will concentrate on specific subjects that have been discovered during the first round as interesting for further investigation. The projects were 
diverse in scope, see Table 4. We developed an interview list with questions from different perspectives and with different questions for the different types of stakeholder. We will not discuss the results of the interviews here, but we confine ourselves to remarking that we are in the process of interpreting the interviews and defining the subjects for the second round of interviews.

Table 4. Projects investigated for their application of DEMO

\begin{tabular}{|l|l|}
\hline $\begin{array}{l}\text { Project name } \\
\text { project organization }\end{array}$ & Characteristics \\
\hline VISI & $\begin{array}{l}\text { Development of a model of large construction projects and } \\
\text { a model for software for exchange of messages for coordi- } \\
\text { nation between project partners }\end{array}$ \\
\hline KLM Air France & $\begin{array}{l}\text { Choice of information system for the merger of the two } \\
\text { cargo divisions }\end{array}$ \\
\hline Rijkswaterstaat & Application Portfolio Rationalization \\
\hline ING & $\begin{array}{l}\text { Implementation of Shared Service Center Securities in a } \\
\text { bank }\end{array}$ \\
\hline
\end{tabular}

\section{Conclusions}

We argued that it is important in research to discern between different aspects while doing IS research. The philosophical assumptions (epistemology) a researcher has, and the methods of doing research he uses, determine the scientific relevance of the things he does. In literature, researchers did try to make sharp distinction between different research methods and to prove that one method is better than another. Other authors tried to prove the similarities of different methods and also there are authors who try to combine different methods into one new method. We believe that it makes more sense to make a combination from different available approaches and justify why this combination is best suited for the situation at hand. Providing a solution for the problems enterprises encounter with ever faster changing markets, requires at first the study of theory and other literature with a positivist attitude. But in nowadays world of Scrum an Lean, applying theory right away in practice is required. For this, $\mathrm{AR}$ is an appropriate approach and the researcher needs an interpretivist stance in applying the solution provided.

\section{References}

1. Dietz, J.L.G., Hoogervorst, J.A.P.: Enterprise Ontology and Enterprise Architecture - how to let them evolve into effective complementary notions. GEAO Journal of Enterprise Architecture 1, 1-19 (2007)

2. Grgecic, D., Rosenkranz, C.: Information Systems Change and Social Interaction: A Research Agenda. In: 18th European Conference on Information Systems (2010) 
3. Chen, D., Vernadat, F.: Standards on Enterprise Integration and Engineering-State of the Art. International Journal of Computer Integrated Manufacturing 17(3), 235-253 (2004)

4. Vernadat, F.: Reengineering the Organization with a Service Orientation. In: Hsu, C. (ed.) Service Enterprise Integration, pp. 77-101. Springer, US (2006)

5. Chen, D., Doumeingts, G., Vernadat, F.: Architectures for Enterprise Integration and Interoperability: Past, Present and Future. Computers in Industry 59(7), 647659 (2008)

6. Dietz, J.L.G.: Architecture: Building Strategy into Design. Sdu Publishing (2008)

7. Myers, M.D.: Qualitative Research in Information Systems. MIS Quarterly 21(2), 241-243 (1997)

8. Williamson, O.E.: Transaction Cost Economics: The Governance of Contractual Relations. Journal of Law and Economics 22(2), 233-261 (1979)

9. Orlikowski, W.J., Baroudi, J.J.: Studying Information Technology in Organizations: Research Approaches and Assumptions. Information Systems Research 2(1), 1-28 (1991)

10. Chua, W.F.: Radical Developments in Accounting Thought. Accounting Review 61(4), 601-632 (1986)

11. Baskerville, R., Wood-Harper, T.: A Critical Perspective on Action Research as a Method for Information Systems Research. Journal of Information Technology 11, 235-246 (1996)

12. Baskerville, R., Myers, M.D.: Special Issue on Action Research in Information Systems: Making IS Research Relevant to Practice. MIS Quarterly 28(3), 329-335 (2004)

13. Yin, R.K.: The Case Study Crisis: Some Answers. Administrative Science Quarterly 65, 58-65 (1981)

14. Benbasat, I., Goldstein, D.K., Mead, M.: The Case Research Strategy in Studies of Information Systems. MIS Quarterly 11(3), 369-386 (2008)

15. March, S.T., Smith, G.F.: Design and Natural Science Research on Information Technology. Decision Support Systems 15(4), 251-266 (1995)

16. Hevner, A.R.: A Three Cycle View of Design Science Research. Scandinavian Journal of Information Systems 19(2), 87-92 (2007)

17. Henderson, J., Venkatraman, N.: Strategic Alignment: Leveraging Information Technology for Transforming Organizations. IBM Systems Journal 38(2\&3), 472484 (1999)

18. Iivari, J.: A Paradigmatic Analysis of Information Systems As a Design Science. Scandinavian Journal of Information Systems 19(2), 39-64 (2007)

19. Peffers, K., Tuunanen, T., Rothenberger, M.A., Chatterjee, S.: A Design Science Research Methodology for Information Systems Research. Journal of Management Information Systems 24(3), 45-77 (2007)

20. Iivari, J., Venable, J.: Action Research and Design Science Research - Seemingly Similar but Decisively Dissimilar. In: Newell, S., Whitley, E.A., Pouloudi, N., Wareham, J., Mathiassen, L. (eds.) 17th European Conference on Information Systems, pp. 1642-1653 (2009)

21. Järvinen, P.: Action Research is Similar to Design Science. Quality \& Quantity 41(1), 37-54 (2007) 
22. Sein, M.K., Henfridsson, O., Purao, S., Rossi, M., Lindgren, R.: Action Design Research. MIS Quarterly 35(1), 37-56 (2011)

23. Orlikowski, W.J.: Using Technology and Constituting Structures; A Practice Lens for Studying Technology in Organizations. Organization Science 11(4), 404-428 (2000)

24. Mulder, H.B.F.: Rapid Enterprise Design. PhD thesis, Technical University Delft (2006)

25. Klein, H.K., Myers, M.D.: A Set of Principles for Conducting and Evaluating Interpretive Field Studies in Information Systems. MIS Quarterly 23(1), 67-94 (1999) 